\title{
Analysis on Teaching Process Design of New Courses from the
}

\section{Postmodern Perspective}

\author{
Qixun Lang ${ }^{1, a}$, Xin Wang ${ }^{1, b}$ \\ ${ }^{1}$ School of Music of Honghe University, Mengzi, Yunnan, China, 661100 \\ ${ }^{\mathrm{a}}$ email, ${ }^{\mathrm{b}}$ email
}

Keywords: Postmodern, Teaching Process, Teaching Process Design, Curriculum Outlooks

\begin{abstract}
New curriculum reform focuses on the dynamic generation of teaching process. The post-modernism are against the traditional teaching design and consider the teaching process should face the diversity of students' living world and uncertainty. In fact, it is the criticism and reflection of the traditional teaching process of curing design thinking. Through the continuous reflection and exploration of the teaching process design, teachers create the subject position of students in curriculum and the joint life experiences of teachers and students.
\end{abstract}

\section{Outlook of Teaching Process from the Postmodern Perspective}

Postmodernism opposes to fix the way to recognize the inherent concept or inheritance, the main purpose is to curriculum should be formed through the interaction of teachers and students in two participants, against the past set in advance of the teaching process, emphasizing the diversity of students' living world and uncertainty, is the traditional rationalism teaching view, center school behavior theory, questioned the authority, in fact for criticism and reflection of the traditional education thought, we are from different angles of deconstruction and understand the increasingly solidified traditional teaching process of thinking.

After the construction of modern curriculum model is non-relativity based on text and meaning on the sequence, rather than a series of fixed knowledge, is learner centered past knowledge, understanding and knowledge of the past existing active interaction, its curriculum design is more rich, interactive, cross will be the more among educators, learners and knowledge building links are more and more, its significance is more deepen. Involved in the teaching process, the main point of view is the following two, designed to lead the entire curriculum design value direction.

Advocate Diversity, Maintain Respect, Coexist Harmoniously. We should respect the difference of students, without discrimination. Postmodernism educators believe that in the past to cultivate obedience, emphasize the teaching goal design, the consistency of the teaching idea greatly harm the individual critical consciousness development, who obey, rather than the creator, for social understanding is often one-sided, seriously out of line with the social life, the so-called social sense of responsibility is usually based on a fictional yearning, lack of sense of social responsibility construction work. In this idea, teaching activities often lack of attention to students' individual differences, and create a large number of one-way degrees of obedience, lack of basic critical awareness, ecological awareness. Therefore, the Postmodernism Curriculum Design emphasizes respect for the students, realize the difference in education, tolerance thinking is different from others "heresy" ideas, and strive to cultivate can identify other value thinking under different cultural backgrounds, understand the relationships with others, society and cultures. In the course of curriculum design, more attention should be paid to the students' subjectivity, curriculum 
design and teaching should be based on the students' different cognition and knowledge background, rather than the one-way.

Postmodern curriculum and teaching view is a kind of reflection on the post modernism educational thought, which has complied with the essential characteristics of the trend of thought: the affirmation of diversity, the denial of authority and the emphasis on innovation. Break all kinds of tyranny and conservative exist in teaching practice, the formation of a new view of curriculum and teaching, teaching activities for the development of a piece of bright heaven.

Change of the Teaching Objective. Postmodernism advocates teaching goal is to cultivate students' ability of knowledge discovery and creation, rather than simply pass the knowledge system, emphasizing the main position in teaching activities, teaching activities of humanity and freedom, is the traditional and modern teaching - respected cultivate rational person, function the doctrine of questioning and criticizing.

Teaching goal should not be to deliver mainstream and dominant culture, shaping the social and cultural subject, and should take into account the particularity of the early experience of different individuals. Students become the unique personality characteristics of talents. At the same time, in order to adapt to the trend of world development and the development trend of world culture, school education to cultivate people should have basic critical consciousness and spirit, dare to question and challenge, to actively accept the different cultural backgrounds, different values, that is to say, education and training people to go beyond the local culture, historical value the concept of personality, become rich and colorful people.

\section{Design Direction of Teaching Process from the Postmodern Perspective}

In the history of school education, including traditional teaching and modern teaching are more emphasis on the teaching process of the preliminary design, which is usually in the sense of lesson preparation. The teaching design of traditional teacher centered, teachers need to understand the teaching content, and make a simple analysis in the teaching process, the role of knowledge dissemination as they reflect, and students are the passive recipients. Therefore, in this way, it is emphasized that teachers actively mobilize the enthusiasm of the students to improve the learning efficiency, the students in a passive state of acceptance. Ye Lan said: "the basic task of teaching is to enable students to learn the experience of the world and social individuals shared the world cultural communication and creative transformation, gradually complete the personal spiritual world of social common spiritual wealth has the personalized and creative nature of possession, give full play to the educational value of mankind's culture, the science of students' active and healthy development." According to the teaching process of post modernism, the author believes that the design of the actual teaching process should focus on the following three aspects.

Joint Life Experiences of Teachers and Students. The emphasis of postmodern curriculum, its essence is to break the traditional teaching philosophy and practice of autocracy, encourage and help the students to understand the world from different angles, the relationship between teachers and students is no longer dull, but full of meaning of life practice. Professor Sun Junsan pointed out: "the fundamental purpose of education is to train people to understand the meaning of the world and the meaning of human existence. Experience is a person's grasp of the meaning of life. The existence of human life is different from the common animal's existence; he has a sense of the meaning of his existence and the world." Therefore, in the design of teaching process, we should pay more attention to children's understanding of different experiences, pay attention to children's life world and let education return to life and teaching process of children, thereby promoting their 
new knowledge of active growth. In this process, teachers and students are alive to meet, rather than the opposition and even one-way degree of autocracy.

Stimulation and Realization of Emotional Goal. School education is not only the process of improving students' cognitive ability, but also the process of cultivating emotions. Emotion is equal to the knowledge, the ability and the skill. It is the same important educational result." In front of it, the traditional view of education and the view of the curriculum have the problem of paying too much attention to the learning of knowledge. In curriculum design, we often find the same problems in the academic evaluation of students: such as classroom comment, academic evaluation, the evaluation purpose is only for students of knowledge assessment, even just a monotonous repetition, and ignore the children's emotional education, in the process of learning experience. The direct consequences not only lead to the students to learn their own emotional resistance, but also hinder the realization of emotional goals, and even the development of students seriously biased. From the perspective of Postmodernism Curriculum pays more attention to the children in class participation and the actual feeling, they think that children's learning process is essential to meet the need of internal drive, therefore, in the course of this design ideas, not only to achieve the education of emotional target can stimulate children's great emotional participation at the same time also can improve the teaching effect.

Subject Position of Students in Curriculum Design. The traditional education ignores the difference between different children's experience world. In the teaching practice, the teaching task usually evolves into the process of the accumulation of the cultural knowledge of students' memory and practice. The post modernism curriculum view should pay attention to the students' subjective experience in the teaching process. Therefore, in the process of teaching design, should strive to create an open, interactive, students actively participate in the atmosphere, the student as the main body of curriculum design, student centered, communicate with each other to set up a student, teacher, knowledge, environment and space, cultivate students' ability of active learning and exploration. The famous educator Sue Home Linsky once said: "there is a need in the ingrained psychological depth. This is the hope that he is a discoverer, researcher, and explorer."

Post modernism advocates that the main task of teaching is to cultivate children's suspicion and criticism of existing knowledge, and then to realize the good vision of liberating children and developing children's creative potential. Although in many researchers, the concept of post-modern education is over estimated that children have the possibility of long-term research and creation, but also for the human being to weaken or even deny the spiritual and cultural wealth. However, it is undeniable that postmodernism in the spirit of the question of epistemology, which is to our current education mode, teaching design is greatly stimulated, to effectively neutralize the traditional teaching concept. Its positive effect is far greater than the disadvantages resulting. Therefore, the understanding of the theory of knowledge and the main body of the theory of the students as the main body of the curriculum design has a great role.

\section{Design Strategies of Teaching Process from the Postmodern Perspective}

The new curriculum reform request teaching gradually toward the students as the main direction of development, and meet the development needs of students, but because of the new curriculum reform is not fully understood, the new curriculum ideas and teaching methods be applied to classroom teaching, the classroom teaching do not have the desired effect." Therefore, it is of great significance to understand and master the strategy of teaching process design.

Objective Analysis of Curriculum Teaching. Course goal analysis is the main part of the teaching process design, which is directly related to the achievement of teaching effect. Teachers 
through the teaching unit of the teaching unit combined with the objective analysis, and then determine the theme of classroom teaching. Such as the combination of teaching content, so that students take the initiative to participate in training their ability to question and reflect.

Theme Circumstance Creation. After determining the teaching subject, teachers should design related to the theme of the situation, and mobilize students learning enthusiasm, the main focus on the learning situation, students should be close to the real life, to provide help to meet the meaning of life of teachers and students to complete the scene, stimulate and Realization of students' affective goal.

Design of Learning Process. According to the different teaching methods, the students' learning process is pre designed, such as the guiding students' shaping design, the collaborative design, or the independent shaping design. Through the learning process design, teachers can estimate the status of the situation, and to find solutions for these conditions, open, found that the classroom is not meant to be unprepared.

Depending on the nature and level of content, learning process design should also be changed. Usually we divide learning into three categories; the first is the basic content. The knowledge content belongs to the easier, and more for the declarative knowledge, assimilation and adaptation or balance of student's individual understanding can satisfy this kind of knowledge is a comprehensive content requirements; two. Usually procedural knowledge based, to use a variety of methods or different methods of learning, learning process design is mainly to train students to master the ability to learn; the three is innovative, developmental content. Such as the development of critical thinking, the development of reflective ability, the questioning of some knowledge and so on, learning process design should be conducive to the cultivation of innovative spirit and practical ability.

Effect Assessment and Feedback Design. It is an important feature of the postmodern curriculum view to replace the single evaluation by the form of evaluation instead of the final evaluation. Therefore, evaluation of the effect of the courses, is the evaluation of the development of early childhood experiences, such as generation of children based on the level of critical awareness, training teachers need to observe continuously and long time, in order to reflect the objective and exact effect. The multiple evaluations refer to the single evaluation method, which is used to replace the scores and classroom performance in the past, as far as possible to relate to many aspects of children's growth. Feedback design should be an important part of teaching process design, which not only directly reflects the children's classroom learning situation, but also is an important resource for teachers to adjust and improve curriculum design.

\section{References}

[1] Ye Lan, Educational Research, Vol. 24 (2002) No 10, p.24-30+50

[2] Sun Junsan, Educational Research, Vol. 23 (2001) No 2, p.34-38

[3] Cai Min, Journal of the Chinese Society of Education, Vol. 25 (2004) No 3, p.52-56

[4] Gu Lingang, Journal of Teaching and Management, Vol. 30 (2013) No 3, p.139-140 